\title{
INLEIDING: \\ DE THEORIE VAN DE MARKETING
}

door Drs. H. W. de Jong

De Italiaanse romanschrijver Alberto Moravia heeft in zijn Racconti Romani een fijnzinnig stukje geschreven over La concorrenza - de concurrentie -.

De hoofdpersoon - hij is in het essay de anonieme ik, maar laten we hem Giacomo noemen - gaat op een dag met een handkar vol sinaasappelen, gedroogde vijgen, walnoten, zoete olijven, pinda's e.d. aan het einde van de brug over de Tiber, tegenover de Gianocolotunnel staan. Het is, wegens de drukte van het passerend publiek, een goed gekozen plaats. De zaken floreren en 's zondags kan Giacomo wel de inhoud van minstens twee karren verkopen. Maar een boerenvrouw met haar bleekachtige, beeldschone dochter vatten op zekere dag met een soortgelijke handkar naast hem post op de brug. De moeder verkoopt; de dochter dient, met zedig terneergesiagen ogen breiend op een stoel, als trekpleister. Tegen de verkoopmethoden van de boerenvrouw, die de klanten de indruk geeft alsof zij een zeer speciale behandeling krijgen, kan Giacomo niet op. Binnen een week verliest hij een groot deel, vooral van zijn mannelijke klanten. Zijn agressieve natuur verleidt hem tot een incident, dat goed afloopt, waarbij hij enige sympathie van de dochter voor hem ontdekt. De betrekkingen worden nauwer en hij doet zelfs een huwelijksvoorstel. Maar weer komt er concurrentie: een slager van de Via Giulia palmt met zijn betere manieren het meisje in en Giacomo veroorzaakt opnieuw een opstootje bij de handkar van zijn concurrenten. Dit keer belandt hij in de gevangenis: de carabinieri betrappen hem met een mes in de hand. Geen wonder, becommentarieert zijn grootvader: je bent de wet van de concurrentie vergeten, verkoop messen, maar gebruik ze niet. Wanneer Giacomo uit de gevangenis komt loopt hij op de Via Giulia langs de slagerswinkel en ziet er de dochter weer zitten breien. Ze is getrouwd met de slager, maar hij zoekt tevergeefs naar andere slagerijen aan de Via Giulia. Er zijn niets dan blikslagers, timmerlieden, marmerwerkers, messenslijpers enz!

De aspecten van het marktgebeuren, waar de commerciële economie zich mee bezig houdt, heeft Moravia in dit essay getekend: innovaties en imitaties, vestigingsplaats en goederenstroom, het potentieel van de markt, assortiment, produktdifferentiatie en verkoopmethoden, fusie en onderhandeling, overtroeven en onderbieden. En achter en door alles heen de wet van de concurrentie: „dicono che la concorrenza é l'anima del commercio” (men zegt dat de concurrentie de ziel van de negotie is). In een passage, die sterk aan A. Smith herinnert, laat Moravia de grootvader zeggen: „dit is het wonderlijke van de wet van de concurrentie: zij dwingt je de consument te bevoordelen, zelfs wanneer je het zelf niet wilt".

Verschillende van de in dit verhaal aangeduide aspecten komen in de hierna volgende artikelen aan de orde. Daardoor ontstaat een weliswaar niet compleet maar toch wel representatief beeld van datgene wat deze sector van de bedrijfseconomie thans te bieden heeft. De bijdragen betreffen alle de relaties van de bedrijfshuishouding met de markt; vandaar dat dit speciale 
nummer van het M.A.B. gepresenteerd wordt onder de vlag: marktaspecten van de bedrijfseconomie.

De rol en betekenis van de markt behoeven voor de ondernemer/zakenman en de practisch georienteerde bedrijfseconoom weinig onderstreping. Vrijwel dagelijks wordt bijna iedere bedrijtshuishouding met de markt geconfronteerd. De onderneming, groot of klein, locaal, nationaal of internationaal vertegenwoordigd - ontleent haar inkomen aan de marktactiviteiten en zij besteedt een groter of kleiner deel van haar uitgaven via de markt. Succes of mislukking op de markt beslissen over het al dan niet voortbestaan van de bedrijfshuishouding, bepalen haar snelheid van expansie of contractie, richten haar doen en laten, en beinvloeden vooral het strategisch beleid dat de ondernemingsleiding voert.

Hoe staat het evenwel met de theorie van markt en marketing? Is marketing überhaupt een wetenschap of beter gesteld, is er een wetenschap van de marketing of is $\mathrm{zij}$, indien niet bestaand, althans in principe mogelijk?

In zijn enkele jaren geleden verschenen artikel, Is marketing a Science, heeft R. D. Buzzell' ) de voorwaarden opgesomd waaraan voldaan moet zijn wil men van een wetenschap van de marketing kunnen spreken. Er bestaat algemene overeenstemming over, aldus Buzzell, dat wetenschap

- een geclassificeerd en gesystematiseerd geheel van kennis is

- dat georganiseerd is rondom één of meer centrale theorieën en een aantal algemene principes

- gewoonlijk uitgedrukt in kwantitatieve termen

- waarvan de inhoud voorspellingen mogelijk maakt en onder sommige omstandigheden, de beheersing van toekomstige gebeurtenissen.

In deze zin, aldus Buzzell, is marketing geen wetenschap, want er bestaat geen centraal thema en er zijn maar weinig aanvaarde principes; voorts is het vermogen tot het doen van voorspellingen zeer beperkt.

De ontwikkeling van het marketing denken geeft evenmin aanleiding om van marketing-theorie(en) te spreken. R. Bartels, die honderden gepubliceerde bronnen gedurende de periode 1900 tot 1960 onderzocht ${ }^{2}$ ), meent dat de meeste bijdragen aan het marketing denken ontstaan zijn vanwege de behoefte bepaalde specifieke marketingproblemen, die opgeld deden in de afgelopen zes decennia, tot een oplossing te brengen. „Dit denken bestaat uit de geaccumuleerde inzichten betreffende de marketing; de feiten van onze markten, regels betreffende hun werking, principes van marketinggedrag en theorieën naar voren gebracht terwille van het bereiken van bepaalde marketing doeleinden."

Wel is er een zeer grote invloed op de ontwikkeling en het voeren van het bedrijfsbeleid in de Verenigde Staten geweest; maar van een algemene marketingtheorie kan niet gesproken worden. In een eerder verschenen $\operatorname{artikel}^{3}$ ) was Bartels hoopvol ten aanzien van de vraag of marketing de status van een wetenschap zou kunnen bereiken. Oorspronkelijk ontstond het marketing denken als een zijlijn van de economie, als gevolg van de veranderingen in de

1) R. D. Buzzell, Is Marketing a Science? In: Harvard Business Review, Jan-Febr. 1963, pag. 33 e.v.

2) R. Bartels, The Development of Markering Thought. Homewood, Ill, 1962

3) R. Bartels, Can Marketing be a Science? Journal of Marketing. Januari 1951, pag. 319 e.v.

$m a b$ blz. 80 
economische omstandigheden aan het einde van de 19e eeuw. Er kwam ,een groeiende dispariteit tussen de feiten en de veronderstellingen die ten grondslag lagen aan de prevalerende economische theorie". Een tweetal van zulke dispariteiten waren van bijzondere betekenis: ten eerste dat, terwijl de traditionele economische theorie ervan uitging dat de producenten zich aan de markt konden en wilden aanpassen, men na 1900 bespeurde dat omgekeerd de producenten meer en meer de markt naar hun hand trachten te zetten. Ten tweede, dat de gangbare economische theorie de positie van de handel nauwelijks ter sprake bracht en in het bijzonder geen inzicht verschafte in de toenemende rol, grootte en diversiteit van zaken als warenhuizen, filiaalbedrijven, postorderbedrijven en (later) supermarkten en discountzaken. De theorie signaleerde noch de feiten, noch verklaarde zij deze, aldus Bartels.

Gegeven deze lacunes koerste men niet zozeer aan op algemeen theoretische verklaringen van de marketingactiviteit op grond van deductieve principes, zoals in de economie gebruikelijk, als wel op de beschrijving van bestaande instituten en praktijken. Het doorsnee Amerikaanse marketingboek groeide onder invloed van dit empiricisme uit tot een turf van honderden pagina's en de series monografieën over uiteenlopende onderwerpen hadden al geen andere inslag. Er werden natuurlijk pogingen tot definitie, classificatie en systematisering ondernomen, in de hoop tot geldige algemene principes te komen, maar de resultaten waren zeer mager. Ofwel de generalisaties waren tautologisch van aard en van weinig nut, ofwel zij waren zo specifiek, dat zij slechts op bijzondere gevallen toepasbaar waren, of wel zij lagen op het terrein van verwante disciplines zoals economie of psychologie ${ }^{4}$ ). Deze benadering, welke nauw aansluit bij de definitie door Bartels van marketing gegeven (,,The field of study which investigates the conditions and laws affecting the distribution of commodities and services"), is daarom weinig vruchtbaar. ${ }^{5}$ )

In een alternatieve benadering, die vooral na de jongste wereldoorlog opkwam, beschouwt men de marketingtheorie als een interdisciplinaire, toegepaste wetenschap. De zuiver economische - soms mechanistische - benadering werd opgegeven terwille van de erkenning van bijdragen uit andere disciplines, zoals sociologie, psychologie, ecologie, anthropologie, en (even later) wiskunde, besliskunde en computerkunde.

Waarschijnlijk de meest ontwikkelde en meest algemene marketingtheorie

4) Voor voorbeelden zie M. Halbert, The Meaning and Sources of Marketing Theory. Mc Graw-Hill Marketing Science Institute Series, 1965, pag. 66/67. Met een tweetal specimen moge worden volstaan: (1) 'when conditions demand modification in the existing marketing structure, the change will be made', (2) 'consumer spending involves both conscious and subconscious decisions to obtain and use goods and services'. Het Nederlandse equivalent van de Amerikaanse marketing-handboeken was in die tijd het leerboek voor organisatie en techniek van de handel, waarvan de kwaliteit - het zij zonder chauvinisme gezegd - als regel beter was.

5) Bartels schrijft in zijn artikel van 1951: "The core, or focal point, of marketing lies in the institutional framework of its technical aspects." en geeft op grond daarvan twee voorbeelden van marketing principes: (1) dat het distributiekanaal des te langer zal zijn voor goederen van lage waarde per eenheid, geringe omvang, algemene consumptie en stapelbaarheid, frequent en regelmatig gekocht door grote aantallen mensen. (2) de afstand welke goederen afleggen op weg naar de markt is een directe functie van het verschil van prijsverschillen tussen twee markten en de transportkosten ertussen. M.i. zijn dat geen marketingprincipes, maar pogingen tot empirische generalisatie, waarvan de empirische inhoud nog geenszins vaststaat. 
in dit genre is die van Wroe Alderson. Deze auteur ziet de marketingtheorie als een onderdeel binnen het theoretisch raam van een algemene wetenschap van het menselijk gedrag. Het bezwaar van Alderson tegen de economische theorie is, dat zij zich vooral bezig houdt met aanpassingsproblemen van de huishouding en niet met overleving of continuiteit (,survival"). De onderneming is volgens Alderson een georganiseerd gedragssysteem, met twee essentiële componenten: een groep mensen die samenwerken, omdat zij daar voordeel van verwachten, en een stel instrumenten en middelen, door deze groep in een bepaald milieu gebruikt.

Ieder dezer gedragsinstrumenten kent een aantal structuurelementen opeenvolging, parallelliteit, circulariteit, centrale tendens, en vereniging (of overeenstemming) - alsmede subsystemen.

Een gedragssysteem tracht nu - en hier verschijnt een biologische analogie zich in een hoek van de markt te vestigen en van daaruit te groeien en bloeien. Maar milieuveranderingen scheppen problemen zowel als mogelijkheden. Wat verklaart het slagen of ondergaan van de onderneming? Alderson geeft drie theorema's, die ieder een factor aanwijzen welke de overlevingskansen van een gedragssysteem bepalen:

1 de leden van het systeem menen meer voordeel te zien in collectief gedrag dan in individueel optreden of de deelneming in een ander systeem.

2 er is een capaciteit tot handelen ondanks concurrentiële aanvallen.

3 gedragspatronen zijn veranderbaar overeenkomstig de eisen die milieuwijzigingen stellen.

Deze beschouwingswijze, welke als doel van het gedragssysteem de overleving aanwijst, betekent een breuk met het traditionele economische gezichtspunt van de efficiency. Alderson onderkent n.l. drie niveau's van evenwicht:

a. het marktevenwicht

$b$. het organisatorisch evenwicht

c. het ecologisch evenwicht.

Groei is een algemene voorwaarde voor het slagen van het georganiseerde gedragssysteem; voorts is een netwerk van beheerscentra, met een centrale beslissingsinstantie, waar de strategische decisies worden genomen, van groot belang.

Onder deze decisies steken er twee boven de anderen uit:

het stellen van de operationele doelstellingen en de keuze van de optimale technologie.

Gedragssystemen kunnen volgens Alderson ook pathologische trekken vertonen, b.v. wanneer de beheersende groep geen richting meer aangeeft, het systeem op traditionele wijze voortgaat en uiteindelijk desintegreert. Of er is te weinig communicatie tussen de lagere en hogere beheerscentra. Of er ontstaat weerstand tegen de leiding, waaruit conflict en rebellie volgen, zodat nieuw leiderschap nieuwe doeleinden moet specificeren en een nieuwe technologie inzetten.

Bijzonder gevaarlijk is wat Alderson de ,extinction mode” noemt: het uitstervingsproces, dat een soort neerwaartse vicieuze spiraal van gedrags-

$m a b \quad b l z .82$ 
systemen is, waaruit bijna geen uitweg, d.w.z. een overgang naar een ander gedragspatroon, mogelijk is.

Alderson noemt zijn theorie een functionalistische, waarvan het doel tweeledig is: het begrijpen hoe de gedragssystemen werken en de vaststelling van de conclusies die daaruit volgen met betrekking tot de verbetering van haar functionering. De titel van zijn hoofdwerk geeft dit dubbele gezichtspunt weer. ${ }^{6}$ )

Alderson's theorie is hier uitvoeriger (hoewel de gedachtengang geen recht doende) weergegeven, omdat de beperkingen aan de conceptie van marketing als een interdisciplinaire gedragstheorie duidelijk naar voren springen. Enige hoofdbezwaren die tegen deze en soortgelijke theorieën zijn aan te voeren zal ik puntsgewijs samenvatten. Daaruit moet evenwel niet geconcludeerd worden, dat deze benaderingswijze niets positiefs te bieden zou hebben; het gaat om de vraag in hoeverre een consistente en relevante marketingtheorie geboden wordt.

1 De biologische analogie is m.i. misleidend, want terwijl het in de evolutietheorie gaat om de instandhouding van de soort, bespreekt Alderson de overleving in termen van een gedragssysteem, d.w.z. van een individuele eenheid. Wetenschap of theorie heeft echter weinig of niets te zeggen omtrent individuele gedragswijzen; zij geeft gegeneraliseerde verklaringen. De hier besproken theorie bereikt dit niveau niet.

2 Overleving of continuiteit is zonder meer geen doelstelling van de onderneming, maar substraat of voorwaarde voor haar bestaan. Doelstellingen zijn subjectief (winstmaken, prestige, concernbouw e.d.) of objectief (bijdrage aan de vervulling van maatschappelijke behoeften) interpreteerbaar en zullen variëren naar gelang van de groeifasen, waarin de onderneming zich bevindt (zie verderop). Hoewel overleving of voortbestaan inderdaad op bepaalde momenten het primaire doel wordt van de onderneming (n.l. wanneer zij op essentiële wijze bedreigd wordt), kan dit desideratum niet gegeneraliseerd worden tot de kern van een algemene marketingtheorie. Als regel is $\mathrm{nl}$. de mogelijkheid dat het tot een totaal échec van de onderneming komt te gering om de besluitvorming te bepalen.

3 Zoals Shapiro heeft uiteengezet is het dikwijls moeilijk om tussen aanpassing reorganisatie en desintegratie te onderscheiden. Evenzo is de afgrenzing tussen een ,georganiseerd gedragssysteem" en het milieu waarin dit werkt meestal niet eenvoudig. ${ }^{7}$ ) Vooral in deze tijd van fusies, overnames en reorganisaties wordt dit duidelijk.

4 Hoewel de interdisciplinaire benadering het perspectief verbreedt, en nieuwe gezichtspunten, begrippen, hypothesen en bevindingen aandraagt, ontstaat er geen marketingtheorie door links en rechts te lenen van naast of verder gelegen wetenschappen. Een wetenschap is meer dan de som van

6) W. Alderson, Marketing Behaviour and Executive Action. Homewood, Ill. 1957.

Eveneens van deze auteur: Survival and Adjustment in Organized Behavior Systems. In: R. Cox and W. Alderson (eds), Theory in Marketing. Homewood, Ill. 1950, en,

A Normative Theory of Marketing Systems. In: Cox, Alderson and Shapiro (eds), Theory in Marketing. Homewood, Ill. 1964 (second series).

7) S. J. Shapiro, The Survival Concept and the Nonprofit Behavior System. In: Theory in Marketing, o.c., pag. 109 e.v. 
elders geleende begrippen, methoden en gegevens. Bovendien wordt marketing op deze wijze een sterk eclectische discipline ${ }^{8}$ ) zonder lijn, zonder de centrale conceptie, die een wezenlijk bestanddeel moet zijn van iedere theorie en waarvan de integratie wordt overgelaten aan de steeds meer gefrusteerde pogingen van studerenden. Het is tenslotte twijfelachtig of een dergelijk conglomeraat geheel van stukken kennis en ervaring wel zal bijdragen tot het anticiperend en prognosticerend vermogen van de theorie.

Maar wellicht is dit alles de noodzakelijke prelude op het fugatisch thema dat komen moet. Wij hebben - te beknopt weliswaar - twee rondes geschetst in de ontwikkeling van het marketing denken: het zoeken naar verschijnselen, gegevens en instituten teneinde via generalisaties theoretisch inzicht te bereiken. Voorts de functionalistisch georiënteerde, interdisciplinaire aanpak, die uitloopt op het ,managerial" gezichtspunt: zeer in trek bij practici ${ }^{9}$ ).

Vanuit wetenschappelijk oogpunt is het echter meer bevredigend de beschouwingen die neerkomen op biologische analogieën, toepassingen van economie of sociale psychologie of algemeenheden resulterend uit gedragssystemen ter zijde te laten en aandacht te schenken aan het centrale verschijnsel: de markt. Daarbij is men er steeds vanuit gegaan dat marketing zich bezig houdt met de vraagstukken verbonden aan het bevorderen van de afzet. Traditioneel was dit het vinden van de klanten voor de gegeven produkten die door de onderneming werden voortgebracht. Meer recent werd daaraan toegevoegd de opdracht om nieuwe (of alternatieve) goederen en diensten te ontwikkelen met het oog op onvervulde wensen van consumenten. En onlangs is door twee auteurs er de aandacht op gevestigd dat een andere dimensie niet vergeten mag worden: het beperken van de algemene of specifieke vraag van consumenten tot het niveau dat de onderneming op korte of lange termijn aankan. ${ }^{10}$ )

De genoemde verschijnselen ontstaan uit het fundamentele gegeven van een markteconomie dat producent en verbruiker gescheiden zijn, maar niettemin op interdependente wijze verbonden. Het optreden als producent veronderstelt in een geavanceerde economie het bestaan van consumenten.

8) 'The author personally views marketing as an 'eclectic' discipline. We borrow heavily from such disciplines as economics, sociology, psychology, cultural anthropology, political science and mathematics. Within the business area, we are indebted for concepts in organizational theory and business statistics' K. K. Cox (ed), Analytical viewpoints in Marketing Management. Englewood Cliffs, New Jersey, 1968. Preface.

$\left.{ }^{9}\right)$ Pogingen tot het opstellen van een algemene marketingtheorie, die de verschillende deeltheorieën omvat worden zo nu en dan ondernomen: tot nu toe met weinig succes.

Zie 0.a. R. Bartels, The General Theory of Marketing. Journal of Marketing, January 1968, p. 29-33, alsmede de critiek hierop van S. D. Hunt, The Morphology of Theory and the General Theory of Marketing. Journal of Marketing, April 1971, p. 65-69.

10) Ph. Kotler and S. J. Levy, Demarketing, yes, demarketing. In: Harvard Business Review, November/December 1971 , p. 74 e.v. De auteurs onderscheiden drie typen van de 'demarketing': (1) algemene 'demarketing', wanneer het gaat om de beperking van de totale vraag, (2) selectieve demarketing, wanneer de vraag van een bepaalde consumentenklasse moet worden gereduceerd en (3) 'ostensible demarketing': het schijnbaar ontmoedigen van vraag, die men in feite wenst te bevorderen. Het laatst genoumde type is o.i. meer een taktiek dan een type van marketing, maar dit laten wij verder rusten. 
Omgekeerd gaat degene die de rol van consument wil vervullen ervan uit dat de middelen om deze rol te spelen hem door producenten kunnen worden verschaft. Tussen consument en producent ligt de markt en deze markt scheidt zowel als verenigt beiden.

De ruilverkeerseconomie accentueert in toenemende mate de separate rol die producenten en consumenten hebben te vervullen. Technische ontwikkeling, arbeidsverdeling en meer gevarieerde consumentenverlangens (gevoed door stijgende per capita inkomens) scheppen voortdurend nieuwe distanties tussen producenten en consumenten, waarbij potentiële markten ontstaan. De potentiële markt representeert een mogelijkheid die nog geen werkelijkheid is geworden. Zij markeert een markt die in aanleg aanwezig is. $\mathrm{Ze}$ is een vacuum zonder een leegte te zijn en daarmede een attractie, een uitdaging op de te ontplooien activiteit van de aanbiedende of vragende onderneming. In de potentiële markt manifesteert zich de scheiding tussen producent en consument als een spanning die overwonnen moet worden. Maar in een vrije ruilverkeersmaatschappij kan deze spanning niet duurzaam op hetzelfde niveau blijven, laat staan verhoogd worden. De concurrentie intervenieert. Gedurende korter of langer tijd kan dit echter wel: het kostte Eastman Kodak enkele jaren om de capaciteit tot produceren van haar Instamatic camera's aan te passen aan de als een lawine opgekomen vraag en Wilkinson Sword moest in het begin der jaren zestig de distributieschakels rantsoeneren toen de onderneming een nieuw roestvrij stalen scheermesje uitbracht! Zolang evenwel de concurrentie functioneert, zal - gelijk Moravia onderkende de potentiële markt geactualiseerd worden, d.w.z. de verbinding tussen producent en consument zal ontstaan. Het vacuum wordt gevuld, de spanning wordt gereduceerd.

Marketing is nu de activiteit welke dit proces van actualisering van de potentiële markt bewerkstelligt.

Anders gesteld: de marketingbezigheid is gericht op de realisering van het marktpotentieel en culmineert in de eigendomsoverdracht van de goederen en diensten, voortgebracht door de producent, in handen van de consument. Weliswaar eindigt de marketing daarmee niet, want - zoals wij zullen zien - de markt heeft een tijdsdimensie, hetgeen impliceert dat de relatie producentconsument een continue kan zijn, zodat de marketing zich ook zal bezighouden met de vraagstukken die volgen op de verkoop (after sales service, b.v.). Door de begripsbepaling van de marketing als een actualiseringsproces van de potentiële markt sluiten wij echter wel de fysieke distributie buiten het marketing-gebeuren - dit in onderscheid met vele (vooral Amerikaanse) auteurs. Voor de marketing is een goed functionerende, soepel verlopende logistieke functie van even groot belang als b.v. de productie der goederen; tenslotte moet het actualiseringsproces ook waar gemaakt worden. Maar evenmin als de productie van de goederen en diensten behoort de logistieke verzorging van afnemers tot haar taak.

Uit de gegeven definitie van de marketing volgen nu enige deducties:

1 Marketing is een proces, dat een reeks handelingen omvat, die zich alle in de tijd voltrekken. Het is daarom een dynamische bezigheid en het vereist de voortdurende bepaling en herwaardering van het marktpotentiëel. Marktre- 
search is het begin en de grondslag van deze marketingactiviteit; zij omvat de analyse van de bestaande markt, de evaluatie van de gebruikte instrumenten en de prognose van de marktontwikkeling (zie het artikel van Verdoorn).

2 Marketing is geen nieuwe bezigheid, maar een nieuwe naam voor het aloude proces waarbij de kloof tussen producent en consument wordt overbrugd door een ruiltransactie. Wel is dit proces door allerlei oorzaken de laatste tientallen jaren in complexiteit gegroeid (en zal het verder blijven groeien), terwijl de urgentie wisselt met tijd en plaats. In de tegenwoordige Westerse economie heeft het actualiseringsproces in vele bedrijfstakken en voor vele ondernemingen een grote mate van urgentie verkregen. Voorts slaat marketing zowel op de verkoop- als op de inkoopzijde van de onderneming; in beide gevallen is het actualiseringsproces van betekenis (zie het artikel van Kraal).

3 De onderneming die met succes de potentiële markt transformeert in een actuele zal (gegeven een overigens goede organisatie en beleidsvoering) haar bestaan gecontinueerd zien. M.a.w. Alderson's ,survival-theorie" draait de orde om: overleving is geen doel, maar ceteris paribus het gevolg van het marketingbeleid van de onderneming. Dat de onderneming de ,ecologische" veranderingen in haar beleid dient te betrekken is buiten kijf; overleving of continuiteit als doelstelling is evenwel een minimalisme dat zich slecht verdraagt met de maximale opgave waarvoor de onderneming zich in relatie tot de markt geplaatst ziet: de actualisering van de potentiële markt.

4 Uit het voorgaande volgt ook dat het aldus omschreven marketingproces naast een feitelijk constaterende, een normatief taakstellende inhoud heeft. M.a.w. er is goede en slechte marketing, waarbij te bedenken valt dat het formuleren van de eisen voor een goede marketing niet steeds eenvoudig zal zijn en van geval tot geval zal verschillen.

$\mathrm{Na}$ deze enkele opmerkingen over het marketingproces wenden wij ons opnieuw tot de theorie van de marketing. Theorie of wetenschap kunnen wij daarbij kortweg omschrijven als ,the articulated vision of experience" (R. D. Laing). De articulatie dient daarbij minstens te bestaan uit het centrale thema en de principes (theorema's) welke wij in het begin van dit artikel als essentieel bestanddeel van iedere wetenschappelijke theorie aangemerkt zagen. Om tot een voldoende niveau van articulatie te geraken is het - zeker voor een jonge discipline als marketing - van groot belang vragen te stellen. De vragen of problemen zijn de dienstknechten van de theorie, zoals R. Kipling het poëtisch uitdrukte: „I keep six honest serving men

They taught me all I knew

Their names are What and Why and When And How and Where and Who."

$\mathrm{Nu}$ wordt dikwijls gesteld dat het denken over de marketing niet tot het niveau van theorievorming is gekomen; sommigen beweren zelfs dat het nooit zover zal komen. Voorzover men bedoelt dat er nog geen geintegreerde marketing-theorie tot ontwikkeling is gebracht valt tegen deze positiekeuze 
vermoedelijk weinig in te brengen. De variëteit van definities die de literatuur oplevert bewijst dat zelfs ten aanzien van de grondconcepties nog weinig overeenstemming heerst. Maar dit betekent o.i. niet dat een geintegreerde marketingtheorie als een gearticuleerde visie omtrent het actualiseringsproces van de potentiële markt niet mogelijk is. En nog minder dat een aantal „principes" of wetten (in de zin van ontwikkelingstendenzen) niet zou bestaan. Enkele zijn zelfs zeer vruchtbaar gebleken en er is tot op heden tenminste een van zeer brede betekenis en toepassing gebleken die zowel bij marketing-practici als bij theoretici instemming heeft gevonden.

Dit is het productcyclus-idee, waarvan, zoals Buzzell terecht opmerkt, het voornaamste voordeel is dat het van nut is bij het verklaren en voorspellen van het concurrentieel gedrag. ${ }^{1}$ ) In een onderzoek, uitgevoerd met het oogmerk om de concurrentieparameters prijs en reclameuitgaven gedurende de produktontwikkelingsstadia van een drietal voedingsmiddelen te testen, werd (1) het bestaan van de productcyclus ook voor dit soort producten bewezen ${ }^{12}$ ) en (2) kon het patroon van het concurrentieel gedrag, zoals afgeleid uit de productcyclustheorie, worden gerelateerd aan de ontwikkelingsstadia.

Het is m.i. niet overdreven de idee van de productcyclus te beschouwen als de belangrijkste ontwikkeling in de marketingtheorie, waaruit naar verschillende kanten nog diverse nieuwe bevindingen zullen kunnen voortvloeien. ${ }^{13}$ )

Daartoe zijn een tweetal stappen essentiëel: ten eerste een verdere theoretische verdieping en verfijning van deze conceptie, wellicht het beste in aansluiting aan het principe van de dalende distinctie van een product met het verloop van de fasen. ${ }^{14}$ ) Ten tweede de entamering van toegepaste onderzoekingen in afzonderlijke bedrijfstakken, waaruit modificaties van de theoretische inzichten zouden kunnen worden verkregen. Op deze wijze kan een vruchtbare wisselwerking tussen theoretisch en empirisch onderzoek ontstaan; als er één ding is dat de natuurwetenschappen aan de gedragswetenschappen hebben te leren, dan is het wel dit ,geven en nemen" van beide takken van onderzoek.

De conceptie is des te meer waardevol daar de micro-economische theorie de laatste tijd weinig substantiële nieuwe inzichten meer schijnt op te leveren met betrekking tot het concurrentieproces, de prijsvorming en het marktgedrag van ondernemingen. Het actualiseringsproces van de potentiële markt voltrekt zich echter steeds in een concurrentiële omgeving en dit wordt ook

11) R. D. Buzzell, Competitive Behavior and Product Life Cycles. Paper presented to the American Marketing Association Conference, June 15, 1966. (onderzoek van de Division of Research, Harvard Business School, in samenwerking met A. C. Nielsen en A. D. Little). De drie produkten waren: instant coffee, frozen juice concentrate en powdered coffee creamers. Zie voor een algemene schets van het verloop van de productcyclus: Th. A. Staudt \& D. A. Taylor, Stages of Market Development and Competitive Rivalry. in: A Managerial Introduction to Marketing, Englewood Cliffs, New Jersey 1965. Chapter 8.

12) Voor andere producten, zoals duurzame consumptiegoederen en geneesmiddelen is het ontwikkelingspatroon al getraceerd. Zie o.a. R. Polli en V. Cook, Validity of the Product Life Cycle. in: Journal of Business, oct. 1969.

13) Zie ook de bijdragen van Breevoord en Leeflang aan dit nummer, alsmede mijn: Marktanalyse en Markttheorie. Leiden 1971.

14 ) Zie G. Mickwitz, Marketing and Competition, Helsingfors 1959 en M. Bell, Marketing-Concepts and Strategy. London 1966, pag. 287-296. 
duidelijk wanneer men in plaats van naar het produkt, naar de bedrijfstypen en -vormen, zoals die de laatste jaren in de distributie-economie ontwikkeld zijn, kijkt. De bijdragen van De Wilde en Daniêls aan dit nummer onderstrepen evenwel dat theorievorming met betrekking tot de schakels van de distributiekanalen - een hoogst belangwekkende conceptie in de marketing een voorshands nog moeilijke zaak is. Hadden de marketing-theoretici nog niet zo lang geleden de veelbelovende gedachte dat met de wheel-of-retailing-theorie een algemeen aanvaardbare, zich over lange perioden uitstrekkende verklaring van de winkeltypen in de distributie-economie kon worden gegeven, recente ontwikkelingen wekken wellicht twijfels hieraan. Toch is het de vraag of er niet meer in deze cyclische concurrentietheorie zit dan oppervlakkig gezien blijkt. Mc Nair, die de wheel of retailing theorie opstelde, presenteerde haar allerminst als een statische of mechanistische verklaring van de organisatietypen in het distributieapparaat, maar zag de start van ,een omwenteling van het wiel" in een innovatie, die in Schumpeteriaanse zin zowel een radicale verschuiving van de kostenfuncties als (bij slagen) een voor de consument aantrekkelijke formule voorstelt. Het streven naar expansie van de ondernemers vergroot dan de bedrijfsomvang, waarbij enerzijds de vaste kosten component toeneemt (zowel absoluut als relatief, in verband met besparingen op variabele, vnl. personeelskosten) en anderzijds, bij volbezetting de kosten (hoe ook uitgedrukt, per eenheid kapitaal, per vierkante voet enz.) dalen. Deze ,expense differential” (Mc Nair) loopt soms zeer hoog op: in de jaren vijftig b.v. jaarlijkse verkopen per square foot in Amerikaanse discountstores van $\$ 300$, in supermarkten $\$ 150$ of meer, in warenhuizen als regel niet meer dan $\$ 100$. Maar het voordeel van de nieuwe bedrijfsvorm vis à vis de oude trekt de imitatoren aan en na snelle groei ontstaat bij de concurrenten in de nieuwe bedrijfsvorm overbezetting (escalatie van aantal ondernemingen en capaciteiten).

Deze is kostbaar en een nieuwe innovatie kan opnieuw tot kostenverlaging leiden. Dat alleen de kostenkant in deze theorie tot haar recht zou komen, is niet geheel juist: zoals Daniels in zijn bijdrage opmerkt, is de consument een gecompliceerd wezen. Ook de welvarende consument is gevoelig voor prijsverlagingen, al was het maar om meer te kunnen besteden aan voor hem aantrekkelijke andere goederen. Dat is een voorname reden waarom de innovaties aanslaan.

Uit genoemde ontwikkeling zou trouwens eveneens de meermalen geconstateerde tendens tot overbezetting in de detailhandel op een meer dynamische wijze verklaard kunnen worden. ${ }^{15}$ )

Het is intussen nog verre van duidelijk hoever zich de geldigheid van deze theorie uitstrekt: betreft het een algemeen verschijnsel of is het slechts beperkt tot de zgn. convenience-goods, zal een steeds stijgend welvaarts-

15) M. Mc. Nair, Significant Trends and Developments in the Postwar Period. in: A. B. Smith (ed.) Competitive Distribution in a Free High-Level Economy, Pittsburg, 1958 (Herdruk in Westing \& Albaum - Modern Marketing Thought, 2nd edition, 1969). Voor de overcapaciteitstheorie uitgaande van een statisch model zie W. A. Lewis, Competition in Retail Trade. Economica, Nov. 1945 en de kritiek hierop van F. L. van Muiswinkel, De Handelsonderneming, 5e druk, 1967, p. 138 e.v. Voorts W. G. McClelland, Costs and Competition in Retailing. London 1966, p. 220 e.v. 
niveau de wentelgang ondermijnen en zullen nieuwe organisatievormen het partroon wijzigen? ${ }^{16}$ )

Het bovenstaande zijn twee voorbeelden van reeds meer bekende, ten dele nog omstreden marketing-theorieën. Er zijn er meer, hoewel niet zoveel (Reilly's Law of Retail Gravitation is een voorbeeld). En waarschijnlijk zullen de meeste practici, die zich met marketingproblemen bezighouden, zich niet erom bekommeren of er al dan niet een geintegreerde theorie bestaat. Maar, afgezien van het feit dat op marketingcolleges en -cursussen theorieën en methoden zullen moeten worden onderwezen wil de academie (met grote of kleine a) bestaansrecht hebben, is de ontwikkeling van één of meer theorieën ook practisch van nut. De boven gegeven definitie b.v. leidt tot de gevolgtrekking dat de marketing instituties - zoals distributievormen, verkoopmethodes e.d. eerder het gevolg dan de oorzaak van het uitoefenen der marketingfuncties zijn.

Met de verschuiving van de spanwijdte tussen marktpotentieel en actualisering verschuiven ook de optimale instituties en verdwijnen soms geheel. Dit induceert een noodzakelijk relativisme t.a.v. bestaande instituten, een relativisme dat vele practici nog vreemd is.

Flexibiliteit kan ook worden gestimuleerd door een brede marketingconceptie. De productcyclustheorie b.v. leidt noodzakelijkerwijs tot de gedachte dat de concurrentie-parameters, gebundeld in wat men de marketingmix pleegt te noemen, wisselende betekenis hebben met de ontwikkelingsstadia. Bij gevolg vereist hun inzet en samenstelling de zorgvuldige analyse van de marktsituatie waarmede de onderneming geconfronteerd is. Deze totaalanalyses worden nog te weinig ondernomen. Voorts, dat de marketingorganisatie al naar gelang van de situatie en de doelstellingen van de onderneming zal dienen te worden aangepast (zie artikel van Ruoff).

De conclusie die uit de bijdragen van de verschillende auteurs kan worden getrokken is dat marketing een complex terrein van activiteit is, dat zich voorshands moeilijk tot theoretische generalisaties leent. Aanzetten tot schematisering zijn aanwezig, waarvan vooral de conceptie van de productcyclus de meest belovende is. Daarbij blijft marketing een interdisciplinaire bezigheid, zonder dat men overigens dient te vervallen in de onmogelijke eis dat men vijf of zes disciplines zou kunnen overzien, laat staan integreren. Tenslotte groeit het inzicht op een bepaald terrein van kennis door een zekere mate van specialisatie en de unificatie van de begripsvorming. Naar onze mening zal de marketingtheorie trouwens het meeste profijt blijven trekken van economische en economisch-statistische onderzoekingen. Hopelijk zullen de bedrijfskundige faculteiten of studierichtingen hieraan in de toekomst een bijdrage leveren.

Marketing ontstond als een beschrijvend onderdeel van de economie. Het krijgt gaandeweg meer theoretische substantie, maar het zal pas volgroeid zijn als wetenschappelijke discipline wanneer het een uitgewerkte en geintegreerde theorie omtrent het ondernemingsgedrag op de dynamische markt heeft te bieden.

16) Vgl. R. Tilman, The Rise of the Conglomerchand. Harvard Business Review, Nov.-Dec. 1971, p. 44 e.v. 